\title{
Wing Technique: A Novel Approach for the Detection of Stator Winding Inter-Turn Short Circuit and Open Circuit Faults in Three Phase Induction Motors
}

\author{
Makarand Sudhakar Ballal*, Deepali Makarand Ballal*, Hiralal M. Suryawanshi ${ }^{\dagger}$, and Mahesh Kumar Mishra* \\ * Extra High Voltage Technical Department, Maharashtra State Electricity Transmission Co. Ltd, Nagpur, India \\ ${ }^{\dagger}$ Dept. of Electrical Eng., Visvesvaraya National Institute of Technology (VNIT), Nagpur, India \\ ${ }^{* *}$ Dept. of Electrical Eng., Indian Institute of Technology Madras (IIT Madras), Chennai, India
}

\begin{abstract}
This paper presents a novel approach based on the loci of instantaneous symmetrical components called "Wing Shape" which requires the measurement of three input stator currents and voltages to diagnose interturn insulation faults in three phase induction motors operating under different loading conditions. In this methodology, the effect of unbalanced supply conditions, constructional imbalances and measurement errors are also investigated. The sizes of the wings determine the loading on the motor and the travel of the wings while their areas determine the degree of severity of the faults. This approach is also applied to detect open circuit faults or single phasing conditions in induction motors. In order to validate this method, experimental results are presented for a $5 \mathrm{hp}$ squirrel cage induction motor. The proposed technique helps improve the reliability, efficiency, and safety of the motor system and industrial plant. It also allows maintenance to be performed in a more efficient manner, since the course of action can be determined based on the type and severity of the fault.
\end{abstract}

Key Words: Induction motors, Interturn faults, Locus of current, Travel of wing $\left(T_{w}\right)$ and area of travel of wing $\left(A_{w}\right)$

\section{INTRODUCTION}

Three phase induction motors are critical for many industrial processes since they are cost effective and robust in performance. Interturn stator winding insulation faults lead to generated heat in the defective region of the winding, which causes the fault to rapidly progress to more severe forms such as phase-to phase and phase to ground faults [1]. For diagnosing inter-turn stator winding faults in three-phase induction motors, Park's vector technique was proposed in [2]. This technique is based on identifying the appearance of an elliptical pattern. The ellipticity increases with the severity of the fault. However, this method does not give a sharp signature. The approach proposed in [3] is based upon an effective negative sequence impedance detector. However, the limitation of this detector is that it may not change in a predictable manner for extremely low levels of deterioration.

Manuscript received Nov. 27, 2010; revised Oct. 29, 2011

Recommended for publication by Associate Editor Jaeho Choi.

$\dagger$ Corresponding Author: hms_1963@rediffmail.com

Tel: +91-712-2801349, Fax: +91-712-2223230, Visvesvaraya Nat'l Inst. of Tech.

* Extra High Voltage Technical Department, Maharashtra State Electricity

Transmission Co. Ltd., India

** Dept. of Electrical Eng., Indian Institute of Technology Madras (IIT Madras), India
The limitation of [3] is overcome in [4] by voltage mismatch detectors. These detectors are sensitive and give better results for unbalanced voltages [4]. These voltage mismatch detectors are more difficult to apply since a training period is needed in order to develop the impedance parameters. A fault indicator, based on monitoring the off-diagonal term of the sequence components impedance matrix is investigated in [5]. However, historical data related to the impedance matrix is required for detection. In [6], an online diagnosis system using motor current signature analysis (MCSA) with signal-and-data-processing algorithms is used. An analytical redundancy method using neural network modeling of the induction motor in the vibration spectra for fault detection and diagnosis is proposed in [7]. Adaptive neural fuzzy based inter-turn short circuit and bearing wear fault detection systems are presented in [8] with a restriction to single-phase induction motors. In [9] a Hebbian-based unsupervised neural network is used to extract the principal components of the stator current data. This data is used to determine the severity of faults. A review of the current literature and the author's experience in the condition monitoring of rotating electrical machinery is presented in [10]. The developments which were reviewed have been proven successful and areas of research which will require attention in the future, to advance the subject, 


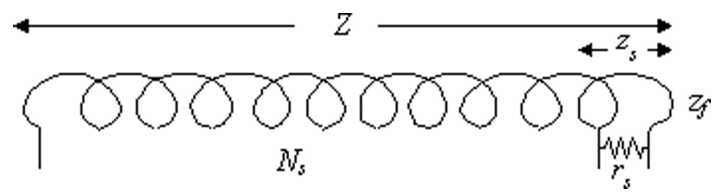

Fig. 1. Inter-turn short circuit fault.

have been identified. A method for motor fault detection, which analyzes a spectrogram based on the short-time Fourier transform and a further combination of wavelet and powerspectral-density (PSD) is explained in [11]. However, this method requires a good knowledge of the signals to find the correct sampling frequency and mother wavelet to improve the detection of faults. In [12] a supervised neural network based diagnostic system is applied in for induction motor drives. However, a number of the neural network modules are trained and tested individually to achieve a true diagnosis of the machine condition.

A comprehensive list of the references published in the last ten years is reported and examined in [13]. It contains diagnostic techniques for electrical machines with a special reference to induction machines. A comprehensive literature survey on the existing methods for low-voltage induction motor winding insulation condition monitoring and fault detection has been presented in [14], and it has determined that turn-to-turn faults account for most induction motor winding insulation faults. In [15], online monitoring techniques for detecting and classifying stator-winding turn faults and highresistance electrical connections for induction machines have been discussed. However, these techniques do not take care of voltage imbalances.

The proposed "Wing Technique" is unique and it detects short circuit faults as well as single phasing or open circuit faults. This is an additional feature which the proposed "Wing Technique" provides. As a result, the blown off fuse of any single phase or single phasing condition can be determined without any additional effort. Therefore, the detection of open circuit or single phasing faults has been included. In this study the loci of the positive $\left(i_{a 1}\right)$ and negative $\left(i_{a 2}\right)$ sequence currents are derived and plotted. These loci currents are dependent upon the three phase motor intake currents. The size of the wings predicts the loading on the motor while the area of the wings and their travel predict the degree of severity of a fault. The area of the wings and their travel reach their maximum values when single phasing occurs. This technique is immune to voltage imbalance variations and it considers inherent asymmetry and measurement errors. This technique leads to an improvement in the reliability of the online stator winding condition monitoring and might be helpful in developing a proactive "as needed" maintenance schedule. This technique is applied to motors of $3 \mathrm{HP}$ and 5 HP. The results are found to be satisfactory.

\section{RELATion OF STATOR Winding INTER-TURn FAUlt WITH STATOR CURRENT AND IMPEDANCE}

Induction machines can be electrically modeled with the coupled magnetic circuit theory. Let the impedance of the complete stator winding of each phase having $N_{s}$ number of turns be $Z$. Therefore, let the impedance of a stator winding per turn $z_{s}$ be defined as:

$$
z_{s}=Z / N_{s} .
$$

The rms value of the stator input current of a particular phase is normal under healthy conditions, and is expressed as:

$$
I_{s} \angle \theta=V_{s} / Z
$$

where $I_{s}$ is the rms value of the stator input current at angle $\theta, V_{s}$ is the rms value of the input supply voltage and $Z$ is the stator impedance under healthy conditions. Whenever an inter-turn short circuit fault takes place, a certain contact resistance between two turns $\left(r_{s}\right)$ comes across where the short is introduced, as shown in Fig. 1. Due to this short, the magnitude of $z_{s}$ decreases to $z_{f}$, as expressed below.

$$
z_{f}=\left(z_{s} r_{s}\right) /\left(z_{s}+r_{s}\right) .
$$

This affects the winding impedance $Z$ depending upon the number of shorted turns. As a larger number of turns gets shorted, $Z$ decreases to $Z_{f}$ [1]. Under constant load and voltage conditions, the decrease in the magnitude of $Z$ increases the stator fault current $\left(I_{s f}\right)$. This is expressed by following equation:

$$
I_{s f} \angle \phi=V_{s} / Z_{f}
$$

where $\phi$ is phase angle of the current and $Z_{f}$ is the stator impedance under unhealthy (interturn short circuit) conditions. Equations (2) and (4) make it possible to write the deviation in the stator intake current as follows:

$$
I_{s d} \angle \delta=I_{s f} \angle \phi-I_{s} \angle \theta
$$

From (5), it is possible to establish the relationship between the stator intake current and the stator interturn fault. Whenever a stator interturn fault occurs, the stator intake current not only varies in amplitude but also in phase displacement. Under healthy winding conditions $I_{s d}=0$ and $\angle \delta=0$. From this observation, it seems to be a negative sequence current and it exhibits unbalances of the stator intake currents due to the interturn short circuit faults. The sequence components of the voltage of a three-phase ac machine in the steady state can be expressed as [5]:

$$
\left[\begin{array}{l}
V_{a 0} \\
V_{a 1} \\
V_{a 2}
\end{array}\right]=\left[\begin{array}{lll}
Z_{00} & Z_{01} & Z_{02} \\
Z_{10} & Z_{11} & Z_{12} \\
Z_{20} & Z_{21} & Z_{22}
\end{array}\right]\left[\begin{array}{c}
I_{a 0} \\
I_{a 1} \\
I_{a 2}
\end{array}\right]
$$

where the subscripts 0,1 and 2 represents the zero, positive and negative sequence components of the voltage and current phasors, respectively, and $Z_{i j}$ represents the impedance of the $i$ sequence due to the $j$ sequence. The $Z_{i j}$ impedances are functions of the motor design, construction, any internal deterioration and operating speed. For an ideal machine, the off diagonal terms of the impedance matrix in (6) are zero and the sequence components are independent of each other (decoupled). Due to the inherent asymmetry of the machine, the off diagonal impedance terms are small non-zero values. Therefore, the sequence components are not decoupled. The ground faults can be easily identified by the standard techniques that monitor the zero-sequence component of the line 


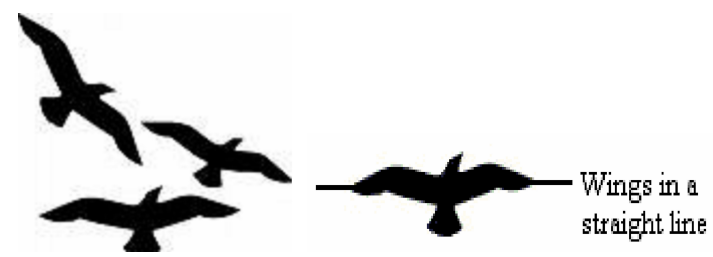

Fig. 2. Flying birds - concept of "Wing Technique".

currents. In this paper, however, it is assumed that $I_{0}=0$. Furthermore, this paper concentrates on the main problem of detecting the inter-turn insulation faults that do not involve the ground. Thus, (6) is modified as:

$$
\left[\begin{array}{l}
I_{a 1} \\
I_{a 2}
\end{array}\right]=\left[\begin{array}{ll}
Z_{11} & Z_{12} \\
Z_{21} & Z_{22}
\end{array}\right]^{-1}\left[\begin{array}{l}
V_{a 1} \\
V_{a 2}
\end{array}\right]
$$

From (7), the deviation in $Z_{21}$, which is used as a turn fault indicator, is defined as [5]:

$$
\Delta Z_{21}=Z_{21}-Z_{210}
$$

Thus, the historical data $Z_{210}$ is required to detect the condition of the winding insulation. This data base is helpful in the process to determine the level of the winding insulation. From (5) and (8), it is inferred that the deviation of the stator intake current and the stator winding impedance increase with the severity of a fault.

\section{Concept of the Wing Technique}

In this section, the "Wing Technique" is presented to diagnose interturn insulation faults. Birds fly freely in the sky as can be seen in Fig. 2. Birds are often relaxed and most enjoy conditions when their wings are in a straight line as the travel of the wing is not necessary. However, under stress or wounded conditions, birds apply more force and therefore wing movements are increased. This phenomenon of birds under the relaxed condition is like an induction motor under the healthy condition and it is explained in this section. Stator turn-to-turn short circuits are one of the more prevalent and potentially destructive electrical faults in induction machines. The only inherent and readily accessible alternative sources of information regarding a machine's health are its terminal voltages and currents. By monitoring these variables, relevant information can be derived to indicate the health of an induction machine [1]. While considering only the fundamental components of electrical excitation, the sum of the line to neutral voltages is given by the following relationship:

$$
V=V_{a}+V_{b}+V_{c}
$$

where:

$$
\left[\begin{array}{l}
V_{a} \\
V_{b} \\
V_{c}
\end{array}\right]=\left[\begin{array}{ccc}
Z_{a} & 0 & 0 \\
0 & Z_{b} & 0 \\
0 & 0 & Z_{c}
\end{array}\right]\left[\begin{array}{c}
I_{a} \\
I_{b} \\
I_{c}
\end{array}\right] .
$$

For an induction motor drawing balanced currents, the three phase sequence impedances are equal, i.e.:

$$
Z_{a}=Z_{b}=Z_{c} .
$$

In the above equations, $V_{a}, V_{b}$ and $V_{c}$ are phase voltages, $I_{a}, I_{b}$ and $I_{c}$ are phase currents and $Z_{a}, Z_{b}$ and $Z_{c}$ are the impedances of each phase, respectively. The subscripts $a, b$ and $c$ represent the three phases $a, b$ and $c$, respectively. In a three-phase connection for a solidly ground, wye connected motor, the sum of the phase currents must be zero for a balanced three-phase system, i.e.:

$$
I_{a}+I_{b}+I_{c}=0
$$

The equation (11), can be written as,

$$
\frac{V_{a}}{Z_{a}}+\frac{V_{b}}{Z_{b}}+\frac{V_{c}}{Z_{c}}=0 .
$$

The unbalance in the magnitude of the currents and phase angles of the three phases of a motor is mainly due to an unbalanced supply voltage, constructional imperfections in the design of the stator winding, instrumentation differences (signal conditioning variance or sensor errors) and inter-turn short circuit faults. If it is due to any of these reasons, the motor intake currents of a three-phase solidly ground, wye connected motor become different and equation (12) becomes invalid. Therefore, equation (12) becomes:

$$
\frac{V_{a}}{Z_{a}}+\frac{V_{b}}{Z_{b}}+\frac{V_{c}}{Z_{c}} \neq 0 .
$$

In order to compensate the voltage imbalance condition, the voltage correction coefficients $\alpha_{a}, \alpha_{b}$ and $\alpha_{c}$ are determined in every cycle of the output voltage by comparing the individual phase voltages with their average values. The stator winding, once designed, remains unaltered unless some type of interturn fault occurs. The constructional imbalance is also taken into account by applying another set of correction coefficients. These asymmetrical correction coefficients are $\beta_{a}, \beta_{b}$ and $\beta_{c}$. They are calculated only when commissioning the motor by comparing the individual phase currents with their average values. Thus, the inherent asymmetries of a machine as well as the instrumentation differences can be compensated. All these correction coefficients are complex in nature and correct the magnitude of the currents and phase angles. Therefore, the magnitude of the currents and phase angles remains constant under healthy conditions. Hence, (13) is written as follows:

$$
\frac{\alpha_{a} \beta_{a} V_{a}}{Z_{a}}+\frac{\alpha_{b} \beta_{b} V_{b}}{Z_{b}}+\frac{\alpha_{c} \beta_{c} V_{c}}{Z_{c}}=0
$$

In this way, the inherent asymmetries of a machine as well as any instrumentation differences can be compensated. Therefore, when an asymmetry in a motor system is detected, there is a change in the asymmetry correction coefficients and the user can select what action should be taken based on what is causing the asymmetry and the application. If a stator turn fault is present, the motor is usually shut down immediately to prevent further damage to the motor and system. This paper mainly focuses on inter-turn stator faults while high-resistance contacts (HRC) faults are not considered.

Under the balanced voltage condition of the magnitude and phase, the locus of vector $i_{a 1}$ and $i_{a 2}$ (equation (7)) is plotted. It is found that the locus of $i_{a 1}$ is an ellipse with anticlockwise rotation. While the locus of vector $i_{a 2}$ is also an ellipse, the rotation is clockwise. Both of these ellipses overlap each other 


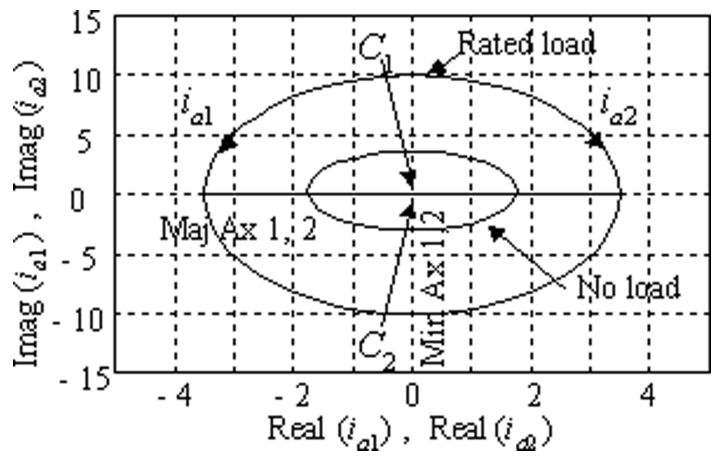

(a)

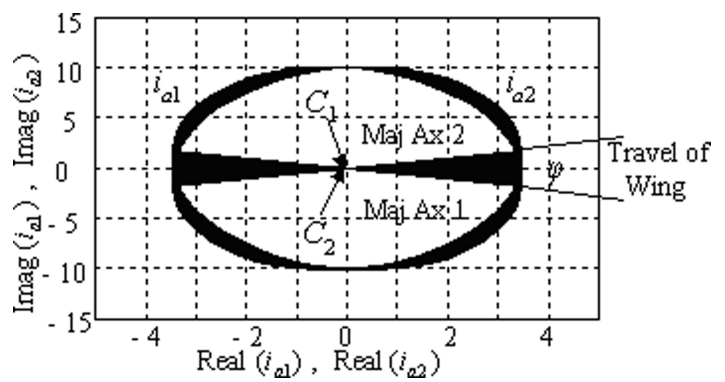

(b)

(Scale: X Axis 1 Ampere / Div. and Y Axis 5 Ampere / Div.)

Fig. 3. Basic idea of loci of $i_{a 1}$ and $i_{a 2}$ for (a) healthy machine, (b) inter-turn shorted machine.

exactly and their centers $\left(C_{1}\right.$ and $\left.C_{2}\right)$ are at one point, as can be seen in Fig 3(a). The major and minor axes of both ellipses are coincide with each other. The area of the ellipses indicates the percentage of loading for the motor. For the no load condition, the elliptical area is smaller and it gradually increases as the motor is loaded. In Fig. 3(a), the inner ellipses illustrate the no load condition and the outer represents the rated load condition.

Whenever an inter-turn short circuit fault occurs, the value of the current for that particular phase not only changes in magnitude but also in phase displacement with respect to the voltage as given in (5). Thus, under abnormal conditions, the motor supply current becomes unbalanced and the locus of vector $i_{a 1}$ becomes more elliptical in shape with an anticlockwise rotation. The locus of vector $i_{a 2}$ also becomes more elliptical but the rotation is clockwise. These two ellipses are not overlapping with each other since their major and minor axes are not coinciding. As a result, a displacement angle $\varphi$ comes into existence between the cross sections of the two major axes of both ellipses. The centers of both of the loci are same but due to $\varphi$, the arc shapes on either side of the center are formed as shown in Fig. 3 (b). These arc shapes look like the wings of a flying bird. These wings are steady when $\varphi$ is zero for the healthy condition and their travel increases with the severity of faults. When a large number of turns are shorted, the magnitude of $\varphi$ increases. As a result, the travel of the wings $\left(T_{w}\right)$ and the area of the travel of each wing $\left(A_{w}\right)$ also increase.

Due to the existence of inter-turn faults, the number of stator winding turns $\left(N_{s}\right)$ gets shortened and the impedance deviation of the winding $\left(\Delta Z_{21}\right)$ of that phase increases. The change in the magnitude of the winding impedance deviation $\left(\Delta Z_{21}\right)$ causes a rise in the stator intake current by $I_{s d} \angle \delta$. Therefore, the displacement $\varphi$ depends upon the winding impedance deviation $\left(\Delta Z_{21}\right)$ and subsequently the current of that particular phase. The displacement $\varphi$ is directly proportional to the winding impedance deviation $\left(\Delta Z_{21}\right)$ and it is inversely proportional to the phase current $\left(I_{s}\right)$. Therefore, the displacement $\varphi$ is a function of the phase current $\left(I_{s}\right)$. These relations are expressed as following set of equations:

$$
\begin{aligned}
& \varphi=f_{1}\left(N_{s}\right) \\
& \varphi=f_{2}\left(\Delta Z_{21}\right) \\
& \varphi=f_{3}\left(I_{s}\right) \\
& \varphi=f_{4}(\text { severity of fault })
\end{aligned}
$$

where the functions $f_{1} \ldots f_{4}$ are different nonlinear functions. From (15), it is known that as more turns $\left(N_{s}\right)$ are shorted, the insulation of the winding becomes poor and as a result, the displacement $\varphi$ increases. Therefore, the insulation condition $\left(N_{c}\right)$ is mentioned in terms of the displacement $\varphi$, the travel of the wings $\left(T_{w}\right)$ and the area of the travel of each wing $\left(A_{w}\right)$.

$$
N_{c}=f_{5}\left(\varphi, T_{w}, A_{w}\right) .
$$

There is a definite relationship or proportional correlation between the number of shorted turns and the magnitude of the displacement $\varphi$. Therefore, it is felt that this correlation can be exploited for diagnostic purposes. The travel of the wing $\left(T_{w}\right)$ and the area of travel $\left(A_{w}\right)$ of each wing are written as follows:

$$
\begin{gathered}
T_{w}=2 r \sin (\varphi / 2) \\
A_{w}=\int_{r=0}^{r=R} r d r \int_{\varphi=0}^{\varphi=\Phi} d \varphi
\end{gathered}
$$

where, $r=\sqrt{r_{x}+r_{y}}, r_{x}$ and $r_{y}$ are the cosine and sine components of radius $r$. It can be seen from (18) that the radius $r$ depicts the load condition of the motor, whereas the displacement angle $\varphi$ indicates the severity of a fault. The maximum values of $r=R$ and $\varphi=\Phi$ depend upon the loading and the severity of a fault, respectively. Therefore, the condition of the motor winding insulation $\left(N_{c}\right)$ can be predicted based upon the displacement $\varphi$, the travel of the wing $\left(T_{w}\right)$ and the area of travel $\left(A_{w}\right)$. Under ideal conditions, when the motor winding is healthy, the displacement $\varphi$ is $0^{\circ}$ i.e., both of the wings are in a straight line with $T_{w}=0$ and the area of travel $A_{w}=0$. However, in practice, due to variation in the supply voltage, inherent asymmetries of machine and instrumentation differences, the displacement $\varphi$ appears with a certain value near $0^{\circ}$ and as a result, travel of the wings appears. However, in this system, the correction coefficients are applied and therefore, for a healthy motor condition, the displacement $\varphi$ is always $0^{\circ}$ and both of the wings are in a straight line. This paper mainly concentrates on interturn short circuit fault of the entire stator winding of a motor in all of its phases.

\section{EXPERIMENTAL RESUlts}

A 5-hp, 4 pole, 415-V, wye-connected induction motor was tested for inter-turn short circuit faults. The parameters of the motor are listed in Table I. The five tapings are provided on the phase- $b$ winding and are taken out to introduce external 
TABLE I

MOTOR SPECIFICATIONS

\begin{tabular}{|c|c|}
\hline Power (hp) & 5 \\
Rated Voltage (V) & 415 \\
Stator winding connection & wye \\
Rated Current (A) & 6.8 \\
Number of poles & 4 \\
Speed in rpm & 1440 \\
Number of turns per phase & 144 \\
Number of rotor bars & 45 \\
Number of stator slots & 36 \\
\hline
\end{tabular}

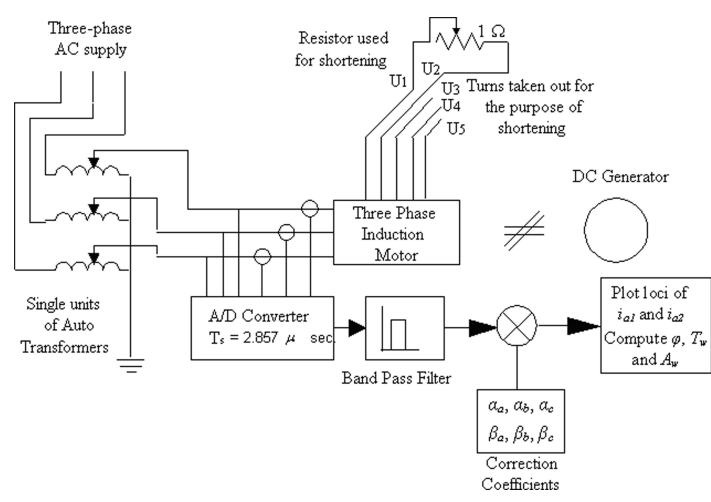

Fig. 4. Functional block diagram.

shorts. These turns are shorted in four steps i.e. two turns per step $\left(U_{1}-U_{2}, U_{1}-U_{3}, U_{1}-U_{4}\right.$ and $\left.U_{1}-U_{5}\right)$. The inter-turn short circuits were achieved through a variable $1 \Omega$ resistor. This resistor is used for safety purposes to avoid sparking when making shorts. Finally, in the steady state, its value is reduced to zero. A functional block diagram is depicted in Fig. 4. The motor is coupled with a dc generator with a $5 \mathrm{~kW}$ rating. The output of the generator is connected to a bank of ten resistors that are individually controlled to provide a wide range of loads.

In this block diagram, the voltage and currents are sensed using Hall Effect voltage and current transducers, a LEM LV 25-P and a LEM LA 55-P, respectively. The sampling frequency of the analog to digital converter is $350 \mathrm{kHz}$. The voltage correction coefficients are computed within consecutive cycles of the stator voltage and are applied to their respective phases. The asymmetry correction coefficients are calculated at the time of commissioning and are applied to compensate the errors due to constructional imbalances and instrumentation differences. The asymmetry correction coefficients calculated for the motor under performance are $\beta_{a}$ $=1.003+\mathrm{j} 0.12, \beta_{b}=0.974+\mathrm{j} 0.28$ and $\beta_{c}=0.991+\mathrm{j} 0.006$ in phases- $a, b$ and $c$, respectively. Under normal conditions for a 415 volt three-phase induction motor, it is expected that the supply voltages should be $V_{a}=239.6 \angle 0^{\circ}, V_{b}=239.6 \angle-120^{\circ}$, and $V_{c}=239.6 \angle+120^{\circ}$. However, for this experiment, the three phase voltages available from the source are $V_{a}=239.6 \angle 18^{\circ}$, $V_{b}=239.6 \angle-120^{\circ}+18^{\circ}$, and $V_{c}=239.6 \angle 120^{\circ}+18^{\circ}$ i.e. all of the voltages are displaced by $18^{\circ}$. Therefore, in this case there is an imbalance due to the phase displacement and this can get compensated by applying voltage correction coefficients. Therefore, the voltage correction coefficients computed by the software program are $\alpha_{a}=\alpha_{b}=\alpha_{c}=0.951056516-\mathrm{j}$ 0.309016994 .

It should be noted that when phase voltages having a variation in magnitude arbitrary of $+5 \%, 0 \%$ and $-5 \%$ made by three individual variacs i.e. $V_{a}=251.58 \angle 18^{\circ}, V_{b}=239.6 \angle$ $120^{\circ}+18^{\circ}$, and $V_{c}=227.62 \angle 120^{\circ}+18^{\circ}$ the displacement $\varphi$ is still $0^{\circ}$ and both of the wings are in a straight line. Therefore, for this instance, the correction coefficients computed and applied are $\alpha_{a}=0.90576811-\mathrm{j} 0.294301899, \alpha_{b}=0.951056516$ - j 0.309016994 and $\alpha_{c}=1.001112122-\mathrm{j} 0.325281046$ for the three phases, respectively. In this way, the system takes care of the conditions due to voltage variations.

The three phase line currents of the motor under healthy and inter-turn fault conditions at the rated load are shown in Fig. 5(a) and (b), respectively. In Fig. 5(b), $i_{b}$ and $i_{b f}$ represent the phase- $b$ current under healthy and unhealthy conditions, respectively. The current $i_{b d}$ is the difference between the healthy and unhealthy phase- $b$ current. It should be noted that this current varies in amplitude and phase, as given in (5). Initially the motor runs under healthy conditions. For each set of collected data the positive and negative sequence components i.e. the currents $\left(i_{a 1}\right.$ and $\left.i_{a 2}\right)$ are calculated using (7) and the wing shapes are plotted using the real and imaginary parts of the sequence currents. From the loci of $i_{a 1}$ and $i_{a 2}$, the displacement $\varphi$ is obtained. A PC based data acquisition system with program code executed in $\mathrm{C}^{++}$is used to compute the displacement angle $\varphi$, the travel of the wing $\left(T_{w}\right)$ and the travel area $\left(A_{w}\right)$.

Fig. 6(a) shows the size of the wings obtained from the loci of the currents $i_{a 1}$ and $i_{a 2}$ corresponding to a healthy motor under no-load, $50 \%$ load and $100 \%$ rated load conditions. An increase in the size of the wings means a greater load on the motor. In Fig. 6 (a), for $100 \%$ load condition, the outer loci of the currents $i_{a 1}$ and $i_{a 2}$ correspond to the currents shown in Fig. 6(a). An inter-turn short circuit fault is created by making a short in the first pair (two turns) i.e. $U_{1}-U_{2}$. The major axes of the loci of the currents $i_{a 1}$ and $i_{a 2}$ do not coincide and the displacement $\varphi$ is not equal to $0^{\circ}$. As can be seen from Fig. 6 (b), under the no load condition the displacement $\varphi$ is $1.52^{\circ}$, the travel of the wing $\left(T_{w}\right)$ is $0.0531 \mathrm{Amp}$ and the area of travel $\left(A_{w}\right)$ is $0.0532 \mathrm{Amp}^{2}$. For the same shorting condition at 50\% and $100 \%$ of the rated load the displacement $\varphi$ increases to $5.62^{\circ}$ and $8.26^{\circ}$, respectively. The remaining three pairs are shorted in steps (i.e. $U_{1}-U_{3}, U_{1}-U_{4}$ and $U_{1}-U_{5}$ ) and the loci of the currents are illustrated in Fig. 6. It can be seen in Fig. 6 (c) that the displacement $\varphi$ reaches to $13.27^{\circ}$ and there is an increment in the travel and area of the wings. Four turns shorted at $100 \%$ of the rated load condition is shown in Fig 6(d). It can be seen that the values of the displacement $\varphi$, the travel of the wing $\left(T_{w}\right)$ and the area of travel $\left(A_{w}\right)$ are $12.49^{\circ}, 0.8377 \mathrm{Amp}$ and $1.6386 \mathrm{Amp}^{2}$, respectively. When all eight turns have been shorted under the rated load, the line currents are depicted in Fig 5(b) and the corresponding loci of the currents $i_{a 1}$ and $i_{a 2}$ are depicted in Fig. 6 (e). All of the measurable result parameters $\varphi, T_{w}$ and $A_{w}$ reach their maximum levels at $20.74^{\circ}, 1.6686 \mathrm{Amp}$ and $3.8881 \mathrm{Amp}^{2}$, respectively.

The open circuit or single phasing fault is also studied in this paper. This fault can takes place due to the blowing of a fuse, the opening of a coil at a junction box, the opening of a coil due to sudden developed stresses, mechanical vibrations 


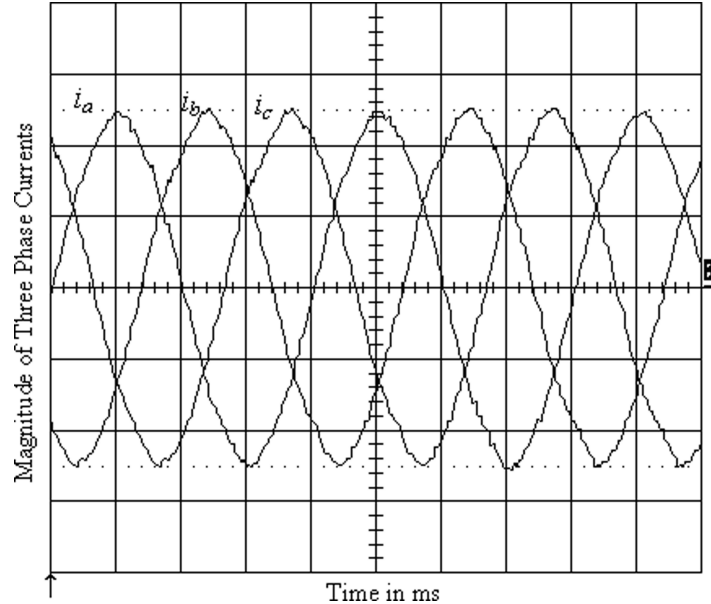

(a)

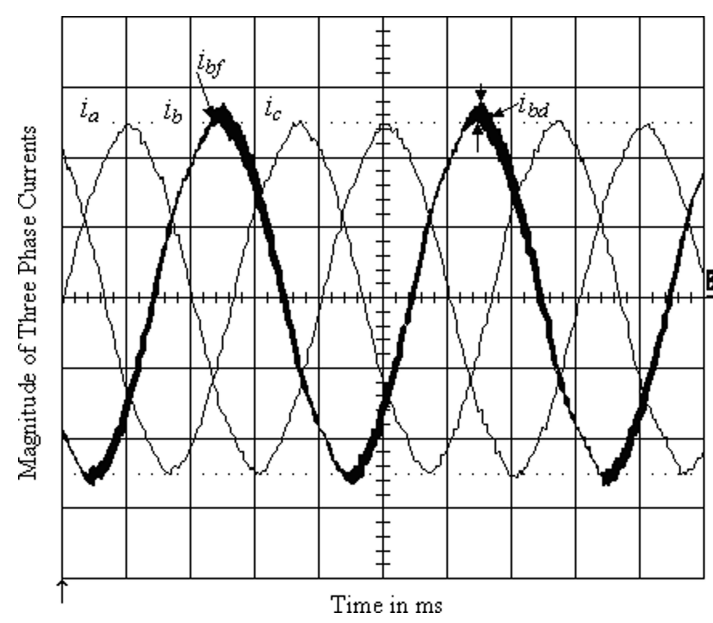

(b)

(Scale: 4 A./div., 5 ms/div.)

Fig. 5. Experimental waveform of line currents for the motor at rated load (a) healthy condition (b) inter-turn fault condition when all eight turns shorted.

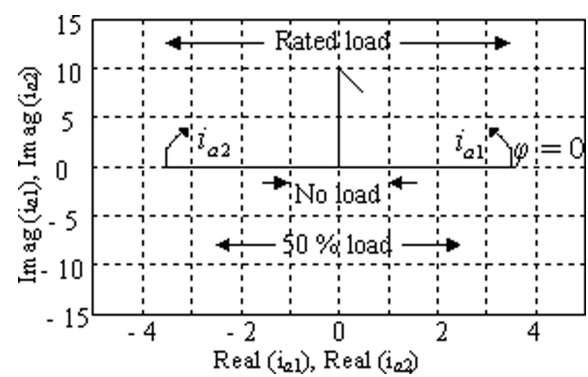

(a)

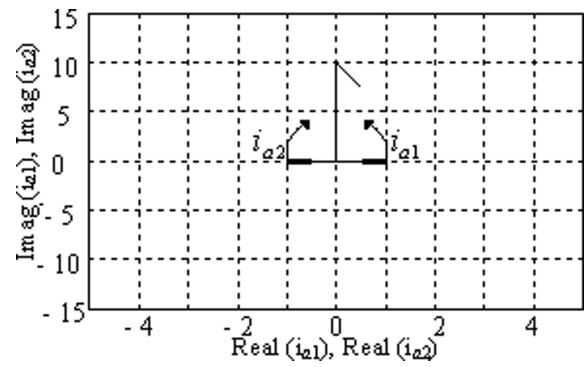

(b)

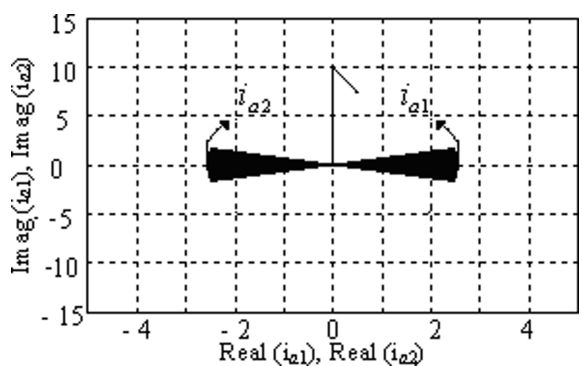

(c)

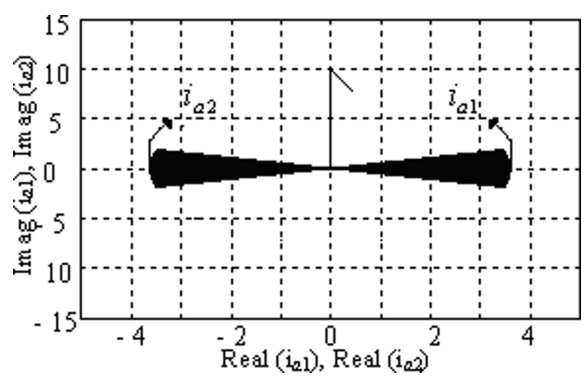

(d)

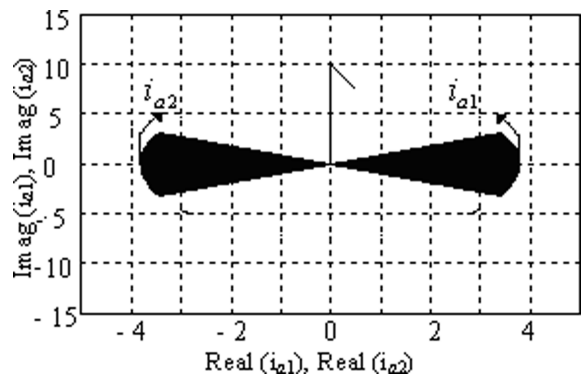

(e)

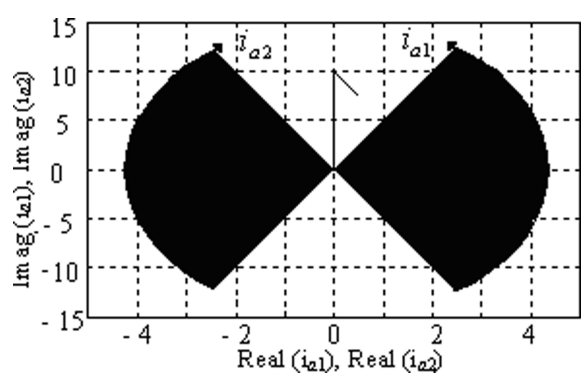

(f)

(Scale : X Axis 1 amp./Div and Y Axis 5 Amp./Div)

Fig. 6. Wings loci of currents $i_{a 1}$ and $i_{a 2}$ for (a) healthy winding condition at different loads, (b) two turns shorted at no load, (c) six turns shorted at $50 \%$ rated load, (d) four turns shorted at $100 \%$ rated load, (e) eight turns shorted at $100 \%$ rated load, (f) phase- $b$ fuse blown off.

of the motor, etc. The phase- $b$ fuse is taken out and the single phasing condition is simulated. Fig. 6 (f) illustrates the results under the rated load condition. The displacement $\varphi$ is $90^{\circ}$ and therefore, both of the parameters $\left(T_{w}, A_{w}\right)$ are at their maximum at this stage. The experimental results show the strength and fidelity of the proposed method.

\section{Conclusions}

In this paper, a simple and reliable "Wing Technique" is developed. This is a unique technique which can detect inter turn short circuit faults and single phasing or open circuit 
faults in a three-phase induction motor. The proposed method is simple low-cost techniques that can be implemented with only voltage and current measurements, without the need for model or parameter information. The results presented confirm the proposed method under various loads and voltage imbalance conditions. The proposed scheme is immune to voltage imbalance variations. It also considers the inherent asymmetry and measurement errors. The correction coefficients $(\alpha$ and $\beta$ ) compensate these nonlinearities.

This technique is very sensitive and accurate. As a result, it has the potential to detect single turn short circuit conditions and thereby detect extremely low levels of deterioration. The shape and size of the wings have a definite correlation with the winding insulation condition. This leads to an improvement in the reliability, efficiency, and safety of motor systems and industrial facilities. In addition, if the two types of faults can be classified, maintenance can be performed in a more flexible and efficient manner, since the course of action can be determined depending on the type and severity of the fault and what is best for a given application. Therefore, this technique is useful for planning a maintenance schedule and it avoids sudden failures thereby avoiding the substantial costs associated with downtime and repair.

\section{ACKNOWLEDGMENT}

Authors of this paper would like to thank the late Mrs. Seema S. Ballal and the late Mr. S. D. Ballal for their preparation and moral support for this paper.

\section{REFERENCES}

[1] P. Vas, Parameter estimation, condition monitoring and diagnosis of electrical machines, Oxford Science Publication, Clarendon Press, Oxford, 1993.

[2] A. J. M. Cardoso, S. M. A. Cruz, and D. S. B. Fonseca, "Inter-turn stator winding fault diagnosis in three phase induction motors, by Park's vector approach," IEEE Trans. Energy Convers., Vol. 14, No 3, pp. 595-598, Sep.1999.

[3] J. L. Kohler, J. Sottile, and F. C. Trutt, "Condition monitoring of stator windings in induction motors: Part I - Experimental investigation of the effective negative-sequence impedance detector," IEEE Tran. Ind. Appl., Vol. 38, No. 5, pp. 1447-1453, Sep./Oct. 2002.

[4] J. Sottile, F. C. Trutt, and J. L. Kohler, "Condition monitoring of stator windings in induction motors: Part II-Experimental investigation of voltage mismatch detectors," IEEE Trans.Ind. Appl., Vol. 38, No. 5, pp. 1454-1459, Sep./Oct. 2002

[5] S.-B. Lee, R. M. Tallam, and T. G. Habetlor, "A robust, on-line, turnfault detection technique for induction machines based on monitoring the sequence components impedance matrix," IEEE Trans. Power Electron., Vol. 18, No. 3, pp. 865-872, May 2003.

[6] J.-H. Jung, J.-J. Lee, and B.-H. Kwon, "Online diagnosis of induction motors using mcsa," IEEE Trans. Ind. Electron., Vol. 53, No. 6, pp. 1842-1852, Dec. 2006.

[7] H. Su and K. T. Chong, "Induction machine condition monitoring using neural network modeling," IEEE Trans. Ind. Electron., Vol. 54, No. 1 pp. 241-249, Feb. 2007.

[8] M. S. Ballal, Z. J. Khan, H. M. Suryawanshi and R. L. Sonolikar, "Adaptive neural fuzzy inference system for the detection of inter-turn insulation and bearing wear fault in induction motor," IEEE Trans. Ind. Electron., Vol. 54, No. 1, pp. 250-259, Feb. 2007.

[9] J. F. Martins, V. Fernão Pires, and A. J. Pires, "Unsupervised neuralnetwork-based algorithm for an on-line diagnosis of three-phase induction motor stator fault," IEEE Trans. Ind. Electron., Vol. 54, No. 1, pp. 259-264, Feb. 2007.
[10] P. J. Tavner, "Review of condition monitoring of rotating electrical machines," IET Electr. Power Appl., Vol. 2, No. 4, pp. 215-247, 2008.

[11] J. Cusidó, L. Romeral, J. A. Ortega, J. A. Rosero, and A. G. Espinosa, "Fault detection in induction machines using power spectral density in wavelet decomposition," IEEE Trans. Ind. Electron., Vol. 55, No. 2, pp. 633-643, Feb. 2008.

[12] G. K. Singh and S. A. S. Al Kazzaz, "Development of an intelligent diagnostic system for induction machine health monitoring," IEEE System Journal, Vol. 2, No. 2, pp. 273-288, Jun. 2008.

[13] A. Bellini, F. Filippetti, C. Tassoni, and G.-A. Capolino, "Advances in diagnostic techniques for induction machines," IEEE Trans. Ind. Electron., Vol. 55, No. 12, pp. 4109-4126, Dec. 2008.

[14] S. Grubic, J. M. Aller, B. Lu, and T. G. Habetler, "A survey on testing and monitoring methods for stator insulation systems of low-voltage induction machines focusing on turn insulation problems," IEEE Trans. Ind. Electron., Vol. 55, No. 12, pp. 4127-4136, Dec. 2008.

[15] J. Yun, K. Lee, K.-W. Lee, S. B. Lee, and J.-Y. Yoo, "Detection and classification of stator turn faults and high-resistance electrical connections for induction machines," IEEE Trans. Ind. Appl., Vol. 45, No. 2, pp. 666-675, Mar./Apr. 2009.

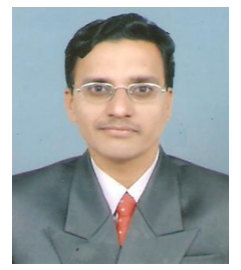

Makarand Sudhakar Ballal received his B.E. in Electrical Engineering from the Government Engineering Collage, Aurangabad, India, in 1993. In 1997, he received his M.Tech. in Integrated Power System from the Visvesvaraya National Institute of Technology (VNIT), Nagpur, India (formerly known as the Visvesvaraya Regional College of Engineering (VRCE)). In 2007, he received his Ph.D. in Electrical Engineering from Rashtrasant Tukadoji Maharaj Nagpur University (RTMNU), Nagpur, India. Dr. M. S. Ballal is presently working as a Deputy Executive Engineer at Maharashtra State Electricity Transmission Company Limited. He has more than fourteen years of experience in the power sector. His current research interests are in the areas of power quality, power system protection and machine fault detection.

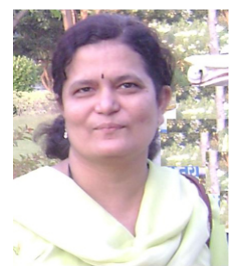

Deepali Makarand Ballal received her B.E. in Electronics Engineering from the Jawaharlal Nehru Collage of Engineering, Aurangabad, India, and a Diploma in Business Management from Marathawada University, Aurangabad, India. She is presently working as an Assistant Engineer at Maharashtra State Electricity Transmission Company Limited. She has more than ten years of experience in the power sector. She has attended various training programs arranged by MSETCL. Her current research interests include power quality, power system protection, etc.

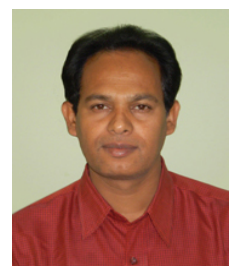

Hiralal M. Suryawanshi was born in Nagpur, India, on January 1, 1963. He received his B.E. in Electrical Engineering from the Walchand College of Engineering, Sangli, India, in 1988 and his M.E. in Electrical Engineering from the Indian Institute of Science, Bangalore, India, in 1994. He received his Ph.D. from Nagpur University, Nagpur, India, in 1998. He is currently working as a Professor and as the Head of the Department of Electrical Engineering, Visvesvaraya National Institute of Technology, Nagpur, India

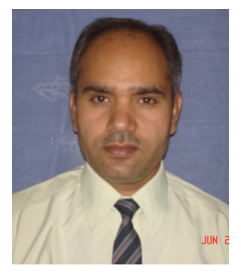

Mahesh Kumar Mishra (S'2000-M'02-SM'10) received his B.Tech. from the College of Technology, Pantnagar, India, and his M.E. from the University of Roorkee, India, in 1991 and 1993, respectively. In February 2002, he received his Ph.D. in Electrical Engineering from the Indian Institute of Technology, Kanpur, India. He has about eighteen years of teaching and research experience. For about ten years, he was a faculty member in the Electrical Engineering Department, Visvesvaraya National Institute of Technology, Nagpur, India. Currently, he is a Professor in the Electrical Engineering Department, Indian Institute of Technology Madras, India. His current research interests include the areas of power distribution systems, power electronics and control systems. 